\title{
Cyclic Behavior Prediction of WUF-W Connections Using FEA
}

\author{
Changseok LEE \\ Department of Architectural Engineering \\ Hanyang University \\ Seoul, Korea \\ e-mail: mtsonicc@gmail.com \\ Taeo KIM \\ Department of Architectural Engineering \\ Hanyang University \\ Seoul, Korea \\ e-mail: tokim27@gmail.com
}

\author{
Namhun KIM \\ Department of Architectural Engineering \\ Hanyang University \\ Seoul, Korea \\ e-mail: namhun_k@nate.com \\ Sangwhan Han \\ Department of Architectural Engineering \\ Hanyang University \\ Seoul, Korea \\ e-mail: swhan82@hanyang.ac.kr
}

\begin{abstract}
The welded unreinforced flange-welded web (WUFW) moment connection is one of seven prequalified connections for the special moment frames (SMF) specified in AISC 358-10. In this study, in order to predict cyclic behavior of WUF-W connections using nonlinear FEA, finite element studies for selection of a proper brick solid element and mesh layer were conducted. As a result, the cyclic behavior of WUF-W connections is evaluated using three-dimensional nonlinear finite element (FE) analyses with an adequate solid element and mesh layers.
\end{abstract}

Keywords-cyclic behavior; moment connection; finite element analysis; special moment frame

\section{INTRODUCTION}

In AISC 358-10 (2010), seven prequalified connections are specified for special moment frames (SMF)[1]. The welded unreinforced flange-welded web (WUF-W) moment connection is one of the permitted SMF connections, which is an all-welded moment connection. According to the commentary of AISC 358-10, the prequalification of the WUF-W moment connection is based on the results of two major research programs conducted at Leigh University and the University of Minnesota. These experimental research program ([2], [3], [4], [5]) reported that WUF-W connections had deformation capacities significantly larger than $4 \%$ drift ratio, satisfying the requirements for SMF connections specified in AISC 341-10 (2010)[6]. Finite element studies were also conducted for developing the special seismic weld access hole and the details of the web connection([7], [8], [9]).

Recently, Reference [10] also conducted experimental tests for WUF-W connections. It was reported that some WUF-W connections with a beam depth of $890 \mathrm{~mm}$ experienced brittle failure and did not satisfy the requirements for SMF connections even though the connections were designed and detailed according to AISC 341-10 and AISC 358-10. It was suspected that the main cause of premature failure in WUF-W connections was the access hole slope. Steep access hole slopes was used in Han et al. (2014), which was $21^{\circ}$. AWS D1.8/D1.8M (2009) specifies that the angle of access hole slope should be less than $25^{\circ}$. [11]

For investigating the effect access hole geometry on the cyclic behavior of WUF-W connections, it is difficult to conduct experimental tests due to excessive costs and efforts. Instead, finite element analyses can be used, which provide detailed stress and strain information at critical regions in WUF-W connections. In this study a three-dimensional (3D) nonlinear finite element analyses (FEA) are conducted to simulate the cyclic curves of WUF-W connections.

\section{THREE DIMENSIONAL FINITE ELEMENT ANALYSES}

In order to simulate the cyclic responses in plastic ranges with FEA, a proper FE software should be chosen. The plasticity models included in software ABAQUS are incremental theories in which the mechanical strain rate is decomposed into an elastic part and a plastic (inelastic) part, which are considered to be sufficient for the analysis of WUF-W connections. Since functions provided in this software are considered to be sufficient for simulating the cyclic behavior of WUF-W connections, this study uses software ABAQUS. This software provides various solid brick elements for nonlinear 3D FEA. In order to obtain accurate FEA results, an accurate element should be used.

\section{A. Material Models}

In order to simulate the cyclic behavior of WUF-W connections via FEA, cyclic coupon tests results are required. Since previous studies did not provide cyclic coupon test results, this study adopts cyclic coupon test results for steel grades A36 and A572-GR50 conducted by Kauffman et al. (1999).[12] Steel grades SS400 ( $F=245 \mathrm{MPa}$ and $\left.F_{u}=400 \mathrm{MPa}\right)$ and SM490 $\left(F_{v}=325 \mathrm{MPa}\right.$ and $\left.F_{u}=490 \mathrm{MPa}\right)$ used for beams and columns of specimen D900-S have similar mechanical properties with steel grades A36 and 
A572-GR50 ( $F_{y}=345 \mathrm{MPa}$ and $\left.F_{u}=450 \mathrm{MPa}\right)$, respectively.

Thus, cyclic coupon test results for A36 and SM 490 conducted by Kauffman et al. (1999) are used to define the cyclic material properties for specimen D900-S, which are shown in Fig.1.

\section{SELECTION OF A PROPER BRICK SOLID ELEMENT}

In ABAQUS, many brick elements are available: the regular brick element with standard integration (C3D8, C3D20), the brick element with an incompatible deformation mode (C3D8I, C3D20I), and the brick element with reduced integration (C3D8R, C3D20R). Element C3D8 is the first order fully integrated element, which overestimates stiffness significantly due to shear locking problem in this element. The first order integrated element C3D8I with incompatible modes was developed to reduce the problem arisen by using element C3D8, but shear locking could not be removed completely. Element C3D8R is the first-order reducedintegration element that eliminates shear locking so that this element can be used for modeling a member dominated by flexure. Since element C3D8R requires reduced integration, this element requires less computation than elements C3D8 and C3D8I. Elements C3D20 and C3D20R second order full and reduced solid elements. Since these elements use more integration points than first order solid elements, the results of FEA are more accurate than those with the first order elements.

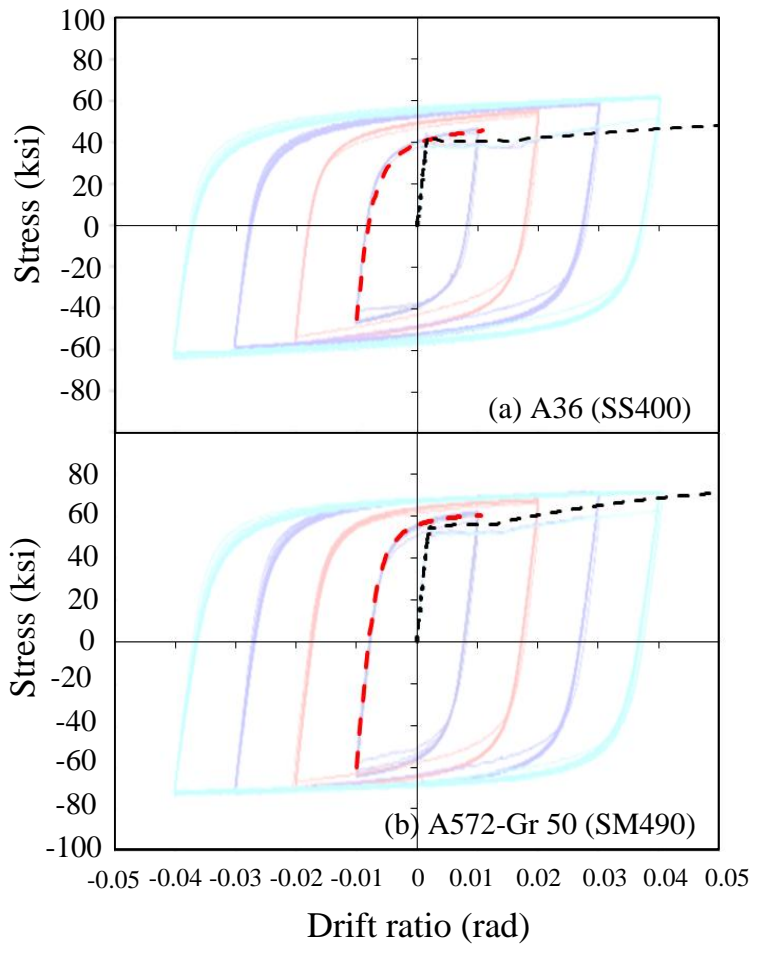

Figure 1. Cyclic stress-strain curves (Kaufmann et al. 1999) for A36 steel and calculated stress-strain curve
However, the second order elements require large computational efforts, which become more excessive with increasing the number of meshes.

In order to select a proper element for WUF-W connections, specimen D900-S is used for FE models. A lower portion of the connection is tested as shown in Fig.2. The support conditions for all boundaries are assumed to be fixed. The tensile force is applied to the beam flange. The components of the connection are divided into four different layers of elements through their thickness (Fig.2).

Fig.3a shows computing time required in FEA with each type of element normalized by that required in FEA with element C3D20 and six layers of elements through the thickness of components. As expected, element C3D20 requires the most computing time among the elements whereas the computing time required using element C3D8R is the least. In Fig. 3b, the distribution of von Mises stress is plotted within the region of stress larger than $85 \%$ of the maximum stress for element C3D20. It is noted that the maximum stresses obtained using different elements are similar irrespective of element types. This study assumes that the stress distribution obtained using element C3D20 is accurate. As shown in Fig.3b, element C3D8R produces a stress distribution that best matches the stress distribution obtained using element C3D20. Thus, considering the computational efficiency and accuracy, this study uses element C3D8R for modeling WUF-W connections.

\section{Minimum LaYers OF ElEMENTS FOR ACCURATE RESULTS}

It is important to determine the optimal number of layers of elements for FEA because computing time increases with increasing the number of layers.

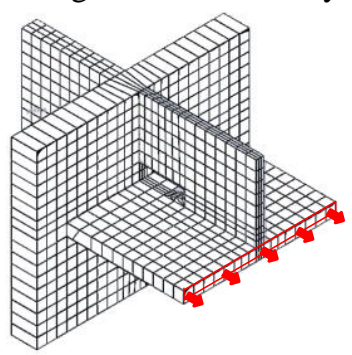

(a) one layer

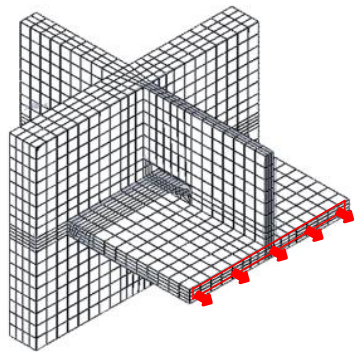

(c) four layers

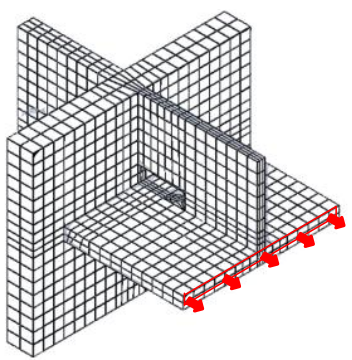

(b) two layers

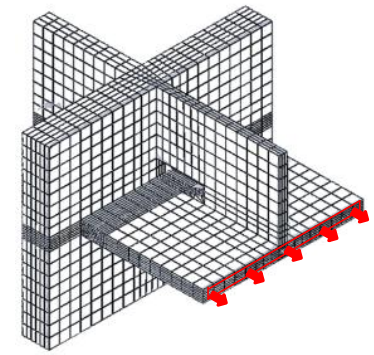

(d) six layer
Figure 2. FE model for lower portion of WUF-W connections 

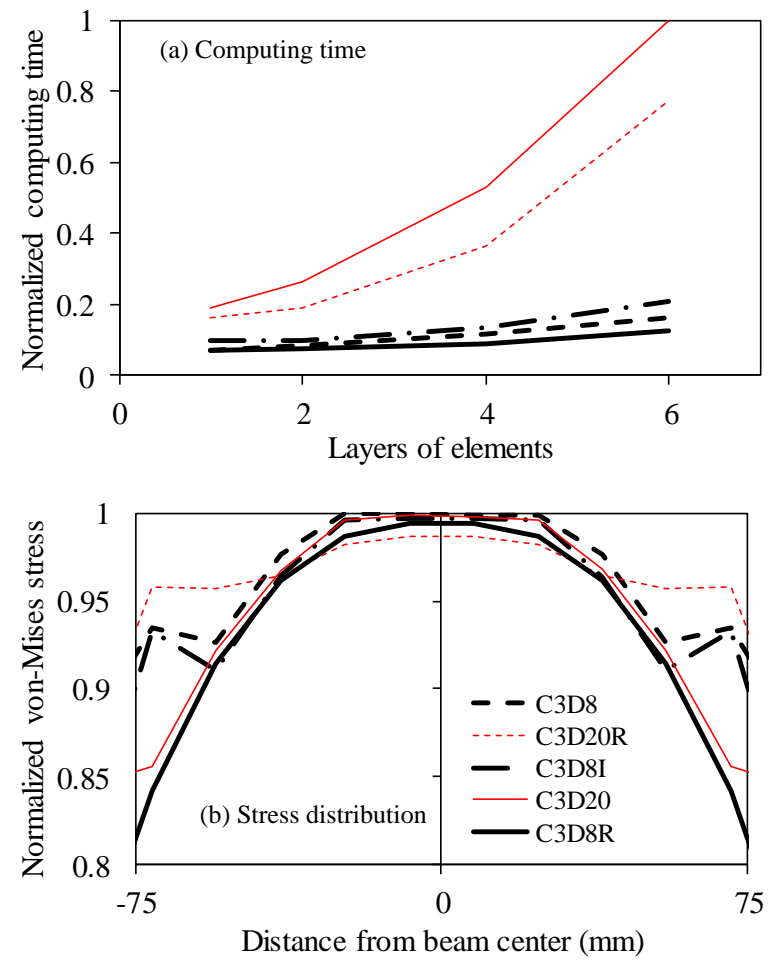

Figure 3. Computing time and distribution of von Mises stress according to different types of elements
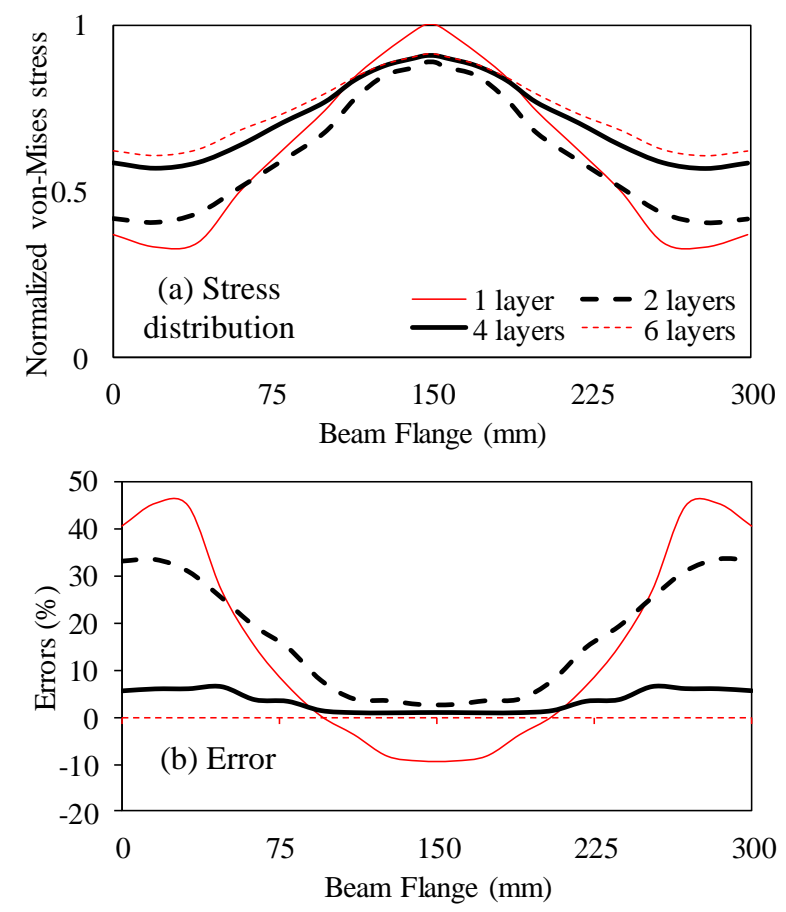

Figure 4. Distribution of von Mises stress according to the layers of elements

FEA are repeatedly conducted with increasing the number of layers until convergence is achieved. Fig. 4 shows the von Mises stress normalized by the maximum stress obtained with single layer of elements (Fig.4a). Fig.4b shows the trend of error $(\%)$ associated with the stress obtained with different element layers. The error is defined as the difference between stresses obtained using multi-1 ayers of elements $\left(\sigma_{n}\right)$ and single layer of element $\left(\sigma_{1}\right)$ normalized by $\sigma_{1}\left[=\left(\sigma_{n}-\sigma_{1}\right) / \sigma_{1} \times 100\right]$. It is observed that the stress distribution obtained with four layers of elements is close to that obtained with six layers of elements. The error associated with four layers of elements is only $6.5 \%$, indicating that the FEA results converges when the number of layers equal to or greater than 4 . Thus, this study divides the thickness of components into four layers as shown in Fig.2c.

\section{Simulating CyCliC CURVES USING Finite ELEMENT ANALYSES FOR WUF-W CONNECTIONS}

The cyclic behavior of WUF-W connections with different access holes are simulated via 3D nonlinear FEA with element C3D8R. The loading histories, support conditions and locations of lateral supports used in FE models are kept the same as those used in the tests. The same displacement controlled cyclic loadings are applied to the specimens as used in the tests. Fig.5 shows the actual and simulated cyclic curves for collected specimens.

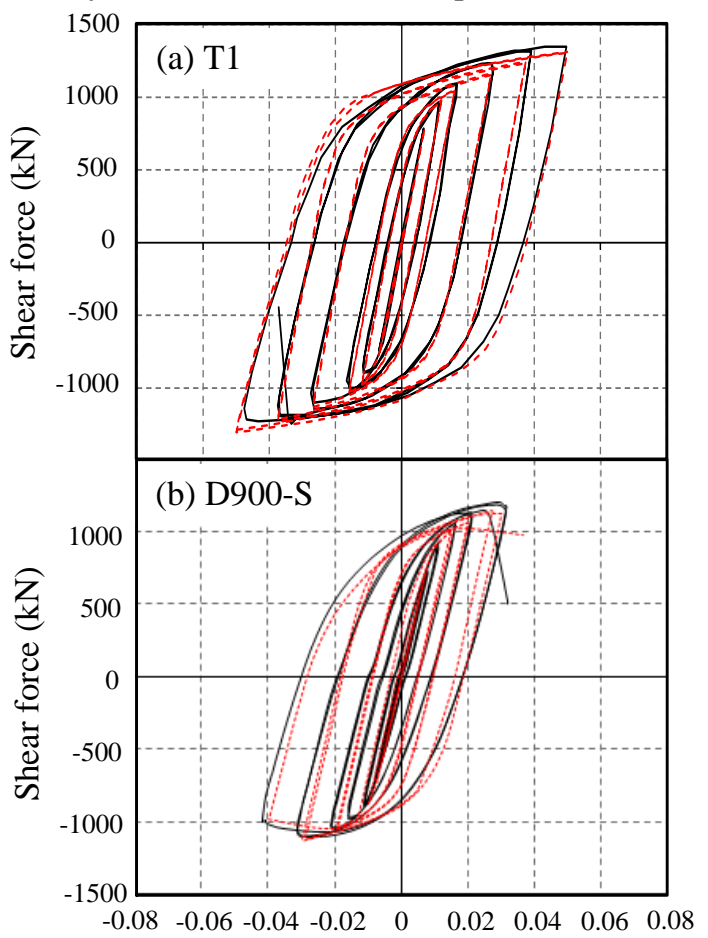

Figure 5. Comparison between Cyclic curves obtained from tests and FEA

The cyclic curves simulated with FEA match those obtained from experimental tests.

\section{CONCLUSIONS}

This study conducted nonlinear 3D FEA to simulate the cyclic curves for WUF-W connections. For computational 
accuracy, stability and convergence, adequate solid element was proposed for FEA, which is element C3D8R. In order to improve the computational accuracy, each component of WUF-W connections was divided into four layers through the thickness of components. The minimum number of the layers was determined as 4, which was obtained by conducting repeated FEA with increasing layers of elements until convergence was achieved. Using the proposed FE model, the cyclic curves of six tested specimens were accurately simulated.

\section{ACKNOWLEDGMENT}

The research was supported by grants from the National

Research Foundation of Korea (No.
2015R1A2A1A15055248).

\section{REFERENCES}

[1] American Institute of Steel Construction Inc. Prequalified connections for special and intermediate steel moment frames for seismic applications, ANSI/AISC 358-10, Chicago, IL. 2010.

[2] Ricles, J.M., Fisher, J.W., Lu, L.W., and Kaufmann, E.J. "Development of improved welded moment connections for earthquake-resistant design.” ASCE Journal of Structural Engineering, 58(19), 565-604. 2000.

[3] Ricles, J.M., Mao, C., Lu, L.W., and Fisher, J.W. "Inelastic cyclic testing of welded unreinforced moment connections." ASCE Journal of Structural Engineering, 128(4), 429-440. 2002.
[4] Lee, D., Cotton, S.C., Hajjar, J.F., Dexter, R.J., and Ye, Y. "Cyclic connections reinforced by alternative column stiffner details I : panel zone behavior and doubler plate detailing." AISC Engineering Journal, 42(4), 189-214. 2005a.

[5] Lee, D., Cotton, S.C., Hajjar, J.F., Dexter, R.J., Ye, Y. "Cyclic connections reinforced by alternative column stiffner details II : panel zone behavior and doubler plate detailing." AISC Engineering Journal, 42(4), 215-238. 2005b.

[6] American Institute of Steel Construction Inc. Seismic provisions for structural steel buildings, ANSI/AISC 341-10, Chicago, IL. 2010.

[7] Lu, L.W., Ricles, J.M., Fisher, J.W. "Critical issues in achieving ductile behavior of welded moment connections." Journal of Constructional Steel Research, 55, 325-341. 2000.

[8] Mao, C., Ricles, J., Lu, L.W., and Fisher, J. "Effect of local details on ductility of welded moment connections," ASCE Journal of Structural Engineering, 127(9), 1036-1044. 2001

[9] El-Tawil, S., Mikesell, T., Vidarsson, E., Kunnath, S.K. Strength and ductility of FR welded-bolted connections, SAC Joint Venture." Rep. No. SAC/BD-98/01, Richmond, CA. 1998.

[10] Han, S.W., Moon, K.H., Jung, J. "Seismic Performance Evaluation of Intermediate Moment Frames with Reduced Beam Section and Bolted Web Connections." Earthquake Spectra, 31(24), 1663-1681. 2014.

[11] American Welding Society. Structural welding code-seismic supplement, AWSD 1.8/D1.8M, Miami FL. 2009.

[12] Kaufmann, E.J. "Characterization of cyclic inelastic strain behavior on properties of A572 Gr.50 and A913 Gr. 50 Rolled Sections." ATLSS Rep. No. 01-13, Bethlegem, PA. 2001. 